\title{
HIDROGEOMORFOLOGIA: PRINCÍPIOS, CONCEITOS, PROCESSOS E APLICAÇÕES
}

\section{HYDROGEOMORPHOLOGY: PRINCIPLES, CONCEPTS, PROCESSES AND APLICATIONS}

\author{
Roberto Fabris Goerl \\ Doutorando do Programa de Pós-Graduação em Geografia da Universidade Federal do Paraná - Laboratório de \\ Hidrogeomorfologia - LHG - Bolsista REUNI - e-mail: roberto.fabris@gmail.com \\ Masato Kobiyama \\ Professor Associado III Departamento de Engenharia Sanitária e Ambiental da Universidade Federal de Santa Catarina \\ - Laboratório de Hidrologia - LabHidro - Bolsista do CNPq - e-mail: kobiyama@ens.ufsc.br \\ Irani dos Santos \\ Professor Adjunto I do Departamento de Geografia da Universidade Federal do Paraná - Laboratório de \\ Hidrogeomorfologia - LHG - e-mail: irani@ufpr.br
}

\section{Informações sobre o Artigo}

Data de Recebimento:

01/06/2011

Data de Aprovação:

01/06/2012

\section{Palavras-chave:}

hidrogeomorfologia;

geomorfologia; hidrologia.

\section{Keywords:}

hydrogeomorphology, geomorphology; hydrology.

\section{Resumo}

O presente trabalho apresenta uma revisão conceitual sobre a Hidrogeomorfologia. Esta ciência foi conceitualmente proposta em 1973 e desde lá vem sido desenvolvida e aplicada em diversas pesquisas. A Hidrogeomorfologia pode ser considerada como a união entre a Hidrologia e a Geomorfologia, sendo que a maneira como esta união ocorre ainda não é muito clara. São apresentadas e analisadas diversas pesquisas que se intitulam de hidrogeomorfológicas e denotam que ainda não há um consenso metodológico e conceitual sobre esta nova ciência. Por fim, o presente trabalho analisou a formação conceitual da Hidrogeomorfologia, seus princípios, processos, aplicações e o seu objeto.

\begin{abstract}
The present work is a conceptual review of the Hydrogeomorphology. This science was conceptually proposed in 1973 and since then has been developed and applied in several studies. The Hydrogeomorphology could be considered as the union between the Hydrology and Geomorphology, however this union is still not very clear. The present paper presents and analysis several studies whose titles contains Hydrogeomorphological studies and consequently concludes that actually there is not a conceptual and methodological consensus on this new branch of knowledge. Finally, the present study examined the conceptual formation of Hydrogeomorphology, its principles, processes, applications and its object.
\end{abstract}




\section{Introdução}

A palavra geomorfologia deriva de três palavras gregas: $\gamma \varepsilon \omega$ (Terra), $\mu о \rho \varphi \eta$ (forma), e $\lambda$ o $о$ os (discurso) (Panizza, 1996; Hugget, 2005). Assim, a geomorfologia trata do estudo das características físicas da superfície da Terra e suas formas, como os rios, montanhas, planícies, praias e dunas. Alguns pesquisadores incluem as formas de relevo submarino no âmbito da geomorfologia (Hugget, 2005).

De maneira geral a geomorfologia é uma área do conhecimento que trata do entendimento e avaliação/apreciação das formas do relevo e da paisagem. Tanto a geomorfologia clássica como a moderna preocupam-se com a classificação e descrição das formas do relevo, os processos e dinâmicas que caracterizam a sua gênese e evolução, além da sua associação e relação com as demais formas e processos (hidrológicos, climáticos, bióticos, tectônicos, antrópicos, entre outros). A geomorfologia é uma ciência empírica que busca formular respostas para questões fundamentais, como: Qual a distinção entre uma forma de relevo e outra? Como as diferentes formas de relevo estão associadas? Como uma paisagem complexa evolui? Quais os processos futuros que poderão agir sobre uma forma ou paisagem? Como o relevo evoluirá? Quais as implicações dos processos geomorfológicos para a sociedade? (Goudie, 2004).

Panizza (1996) argumenta que o principal objeto de estudo da geomorfologia é a superfície de contato entre a litosfera e a atmosfera ou/e hidrosfera, ou seja, a interface entre duas entidades físicas: um meio sólido e outro líquido e/ou gasoso, pois é ao longo dessa superfície de contato (interface) que os processos geomorfológicos ocorrem.

Observa-se, assim, que a geomorfologia trata da paisagem, especialmente a natural. Segundo Goudie (2004), para melhor entendimento das formas e processos e devido à variação temporal e espacial dos mesmos, a geomorfologia moderna subdividiu-se em linhas e domínios especializados:

- Geomorfologia Fluvial: trata das águas correntes, com ênfase em rios, córregos e canais, ou seja, com a parte terrestre do ciclo hidrológico, evolução da bacia hidrográfica e seus processos fluviais correlatos;

- Geomorfologia de Encosta: trata das propriedades geotécnicas do solo e das rochas, os mecanismos de ocorrência de deslizamentos e do movimento da água no solo;

- Geomorfologia Tectônica: estuda a neotectonica, bacias sedimentares em escala continental, bordas continentais ativas/passivas;

- Geomorfologia Glacial/Periglacial: trata das formas e processos resultantes da ação da neve, gelo/geleiras e frost.
- Geomorfologia Cárstica: estuda as rochas solúveis/ carbonáticas e os processos químicos de dissolução;

- Geomorfologia Costeira: estuda a linha de costa; os sistemas lacustres e marinhos;

- Geomorfologia Eólica: estuda o transporte de areia e demais partículas sólidas pelo vento, principalmente em ambientes áridos e semi-áridos.

Nota-se que, para o desenvolvimento dos estudos geomorfológicos, há a necessidade do auxílio de outras ciências. É praticamente impossível, por exemplo, o estudo da geomorfologia fluvial ou de encosta sem o auxílio ou complemento da hidrologia, climatologia ou meteorologia, assim como para o estudo da geomorfologia tectônica, o auxílio da física, geofísica e geologia. A geomorfologia caracteriza-se assim como uma ciência multidisciplinar que se comunica com outras ciências para o avanço dos seus conhecimentos.

Ao analisar as principais linhas acima elencadas, observa-se que exceto a tectônica e a eólica não possuem a água como um de seus agentes primordiais, e as duas primeiras são as que possuem uma maior influência do ciclo hidrológico. Neste contexto (geomorfologia + hidrologia) é que Scheidegger (1973) introduz o termo Hidrogeomorfologia. Assim, o presente trabalho tem por objetivo analisar a formação conceitual da Hidrogeomorfologia, seus princípios, processos, aplicações e o seu objeto.

\section{Histórico da Hidrogeomorfologia}

Apesar de alguma incerteza, pode-se considerar Scheidegger (1973) como o primeiro pesquisador a usar a palavra Hidrogeomorfologia em um artigo científico, publicado no Journal of Hydrology. Além do emprego da palavra, Scheidegger também a conceitua. Na mesma década, Gregory (1979a; 1979b) faz uma reflexão crítica sobre o emprego deste novo conceito e comenta como a espacialização dos processos hidrológicos contribuiu para o avanço dos estudos nas bacias inglesas. Praticamente uma década se passa até o termo Hidrogeomorfologia ser empregado novamente, em Richards (1988), que argumenta que o estudo/conhecimento hidrogeomorfológico regional proporciona o entendimento do cenário de previsão do ajuste/evolução dos rios/sistema fluvial em escala de bacia.

Okunishi (1994) realizou uma pesquisa bibliográfica sobre artigos na temática da Hidrogeomorfologia e sobre os que aplicaram em seus estudos conjuntamente a hidrologia e geomorfologia (Tabela 1), em duas bases de indexação de periódicos (ISNPEC-A e MORPHO). 
Tabela 1-Número deartigos com o termoHidrogeomorfologia e aplicação conjunta da hidrologia e da geomorfologia por periódico

\begin{tabular}{|lc}
\hline Periódico & N $^{\mathbf{0}}$ de Art. \\
\hline Transactions, Japanese Geomorphology Union & 15 \\
\hline Earth Surface Processes and Landforms & 14 \\
Water Resource Research & 08 \\
Journal of Geophysical Research (AGU) & 08 \\
Disaster Prevention Research Institute, Kyoto & 05 \\
Univ. (Annuals e Bulletins) & 03 \\
Hydrological Processes & 02 \\
IAHS Publication & 15 \\
Outros &
\end{tabular}

Fonte: Modificado de Okunishi (1994)

A partir desta coleta, este autor classificou os artigos quanto a sua temática (Tabela 2) para inquirir sobre o estado da arte da Hidrogeomorfologia e suas tendências científicas. Observa-se que artigos relacionados à (A) e (B) não são restritos a Hidrogeomorfologia. Artigos relacionados à (C) e (D) abordam o principal objeto da Hidrogeomorfologia e a Hidrogeomorfologia aplicada, respectivamente (Okunishi, 1994).

Tabela 2 - Classificação dos artigos relacionados à Hidrogeomorfologia

\begin{tabular}{l|c}
\hline Tema de pesquisa principal & $\mathbf{N}^{\mathbf{0}}$ de Art. \\
\hline $\begin{array}{l}\text { (A) Controles topográficos ou litológicos de processos } \\
\text { hidrológicos }\end{array}$ & 13 \\
\hline $\begin{array}{l}\text { (B) Efeitos hidrológicos em movimentos de massa e } \\
\text { processos geomorfológicos }\end{array}$ & 10 \\
\hline $\begin{array}{l}\text { (C) Sistemas Hidrológicos e seus processos correlatos } \\
\text { (D) Diagnóstico e Avaliação Ambiental de sistemas } \\
\text { hidrogeomorfológicos }\end{array}$ & 78 \\
\hline
\end{tabular}

Fonte: Modificado de Okunishi (1994)

A partir da década de 90 a Hidrogeomorfologia recebeu uma maior notoriedade e, a partir do ano 2000, tornou-se um tema recorrente e de maior evidência nos periódicos. A Tabela 3 apresenta a quantidade de artigos em que aparece, por periódico, o termo Hidrogeomorfologia. Foram escolhidos os principais periódicos na temática hidrológica e geomorfológica. Apesar de não ser completa, a tabela apresenta a evolução do uso do tema. Observa-se também que o periódico Hydrological Processes é o que mais se destaca.

Este elevado número de artigos na Hydrological Processes deve-se, em parte, a uma edição especial sobre Hidrogeomorfologia em 2004. Neste número especial foram publicados 14 artigos selecionados e apresentados no eixo temático "Interaction between geomorphic changes and hydrological circulation" durante o "Fifth International Conference on Geomorphology (ICG-5)” (Sidle e Onda, 2004).
Assim, artigos selecionados de uma seção de um Simpósio de geomorfologia foram publicados em um periódico de hidrologia. Isto porque, conforme Sidle (comunicação pessoal), alguns periódicos de geomorfologia não aceitaram a ideia de publicar um número especial sobre Hidrogeomorfologia e, após recusas, a Hydrological Processes aceitou. Isto talvez explique porque Scheidegger (1973) publicou o primeiro artigo que se tem registro sobre a Hidrogeomorfologia em um periódico de hidrologia (Journal of Hydrology).

Tabela 3 - Principais periódicos que contém o termo Hidrogeomorfologia e sua evolução temporal

\begin{tabular}{|c|c|c|c|c|c|c|c|c|c|c|c|c|}
\hline Ano & $7379 \mid 88$ & 895 & 96 & \begin{tabular}{|c|cccc}
99 & 00 \\
\end{tabular} & \begin{tabular}{l|l|l}
0 & 01 & 02 \\
\end{tabular} & \begin{tabular}{ll|l|l|l|l}
02 & 03 & 04 & 0 \\
\end{tabular} & 05 & 06 . & 0708 & 809 & 10 & Total \\
\hline J. Hydrology & 1 & & & 0 & & & & 3 & & 0 & & 5 \\
\hline Geomorphology & 0 & & 3 & & 0 & 1 & 0 & & 2 & 0 & 1 & 8 \\
\hline Earth Surface Processes and Landforms & & & & 0 & & & 1 & 1 & 2 & 0 & & 4 \\
\hline Hydrological Processes & 0 & & & \begin{tabular}{|l|l|lllll} 
& 2 & 2 \\
\end{tabular} & \begin{tabular}{l|l}
2 & 0 \\
\end{tabular} & \begin{tabular}{l|l|l|l|l}
0 & 1 & 18 & 2 \\
\end{tabular} & 2 & 3 & & & 0 & 32 \\
\hline Progress in Physical Geography & \begin{tabular}{l|l}
2 & 1 \\
\end{tabular} & 1 & 0 & 2 & & 0 & & 1 & & 0 & & 7 \\
\hline Revista Brasileira de Geomorfologia & & & & 0 & & & & 1 & & 0 & & 1 \\
\hline Revista Brasileira de Recursos Hidricos & & & & & 0 & 0 & & & & & & 0 \\
\hline
\end{tabular}

Nota-se que há uma diferença entre a Tabela 2 e Tabela 3 referente ao número de artigos publicados na Hydrological Processes. Esta diferença ocorre devido às datas da pesquisa bibliográfica e também das bases de indexação, pois Okunishi publicou seu trabalho em 1994 e fez a pesquisa em apenas duas bases indexadoras.

\section{Princípios da Hidrogeomorfologia}

Scheidegger (1973) foi o primeiro a definir Hidrogeomorfologia como sendo o estudo das formas causadas pela ação das águas, sendo que, por esta definição, quase toda a geomorfologia pode ser enquadrada como tal, pois a água é o principal agente modelador da paisagem. Aproximadamente duas décadas depois, Okunishi (1991, 1994) definiu-a como sendo o estudo entre as interações dos processos hidrológicos e geomorfológicos, mais especificamente a interação entre os sistemas fluviais e de vertente. Propôs ainda uma escala temporal entre os processos hidrogeomorfológicos, geomorfológicos e geológicos. Nesta escala, os processos hidrológicos e os geomorfológicos interagem simultaneamente (hidrogeomorfologicamente) em um intervalo de até $10^{1}$ anos. Os processos geomorfológicos ocorrem entre $10^{1}$ a $10^{5}$ anos e os geológicos após $10^{6}$ anos. Contudo, processos geológicos também podem ocorrer em escalas temporais menores, podendo ser inferiores à escala hidrogeomorfológica, como os terremotos e vulcanismo.

Modificando a escala apresentada por Okunishi (1994), o presente trabalho propõe uma nova escala temporal (Figura 1). Nesta proposta, os processos hidrogeomorfológicos (HG) e hidrológicos $(\mathrm{H})$ ocorrem em até $10^{1}$ anos. Os processos geomorfológicos ocorrem em até $10^{5}$ anos. Já os processos 
geológicos podem ocorrer em qualquer escala temporal, como um terremoto (segundos) ou a formação de um continente (milhões de anos).

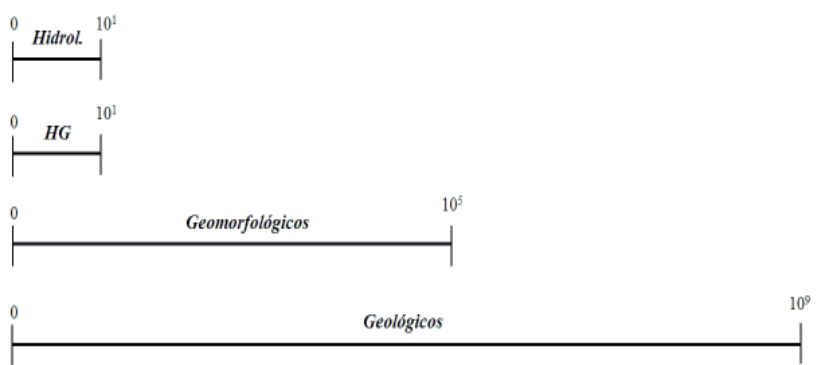

Figura 1 - Escala temporal dos processos hidrológicos (Hidrol.), hidrogeomorfológicos $(H G)$, geomorfológicos e geológicos.

Para Sidle e Onda (2004), a Hidrogeomorfologia, como o próprio nome indica, inclui as inter-relações entre diversos processos hidrológicos e geomorfológicos e pode ser definida como uma ciência interdisciplinar que se concentra na ligação e interação de processos hidrológicos com as formas da paisagem ou materiais terrestres e, ainda, a interação de processos geomorfológicos com as águas superficiais ou subsuperficiais em diferentes escalas espaciais e temporais.

Goudie (2004) designa a interação entre a hidrologia e geomorfologia de Geomorfologia Hidrológica, ou seja, um ramo da geomorfologia. Este autor comenta que a dinâmica das áreas superficiais é o principal elo de interação com a hidrologia e que recentemente pesquisas conjuntas entre a geomorfologia e águas subterrâneas e/ou hidrogeologia tem sido desenvolvidas.

Para Babar (2005), o termo Hidrogeomorfologia pode ser divido em três termos: "hidro" que incorpora as águas superficiais e subterrâneas; "geo" que incorpora a terra e "morfologia", que é expressão das características superficiais nas formas da paisagem. Sintetizando, a Hidrogeomorfologia trata dos aspectos da água, rochas e feições morfológicas da superfície. Este mesmo autor argumenta que, atualmente, pesquisas na área da Hidrogeomorfologia tratam da explicação da paisagem, suas formas e evolução: quais são as formas, qual sua função e como têm se desenvolvido em relação às condições hidrológicas.

DeBarry (2004) define a Hidrogeomorfologia como sendo o estudo dos impactos dos processos hidrológicos sobre a superfície.

Analisando as definições acima apresentadas, percebese que é consenso que a Hidrogeomorfologia é a união da geomorfologia ou hidrologia, embora o entendimento dessa união não esteja ainda de forma clara.

No presente trabalho são propostos três modelos da relação entre a Hidrologia e Geomorfologia. A primeira re- lação sugere uma superposição das duas ciências entre suas áreas comuns (Figura 2a), sem necessariamente haver uma interface entre elas, ou seja, cada ciência aplica métodos semelhantes, mas sem interação entre si. O segundo modelo trata da intersecção entre a hidrologia e geomorfologia, daquilo que se torna o objeto comum às duas ciências (Figura 2b). Neste sentido corrobora Okunishi (1994), para o qual a Hidrogeomorfologia é um pouco hidrologia e um pouco geomorfologia. O terceiro modelo diz respeito à Hidrogeomorfologia como ciência própria, que incorpora elementos da hidrologia, da geomorfologia, além de possuir atributos próprios (Figura 2c).

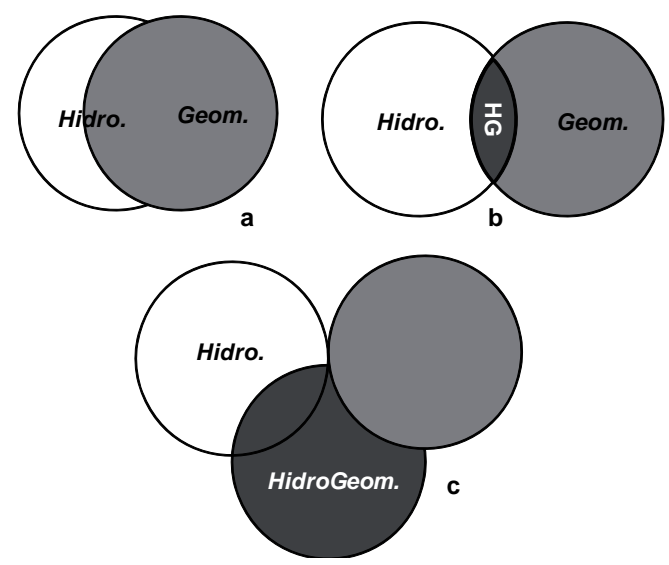

Figura 2 - Modelos conceituais de três interações entre a Geomorfologia, Hidrologia e Hidrogeomorfologia: a) sobreposição, b) intersecção e c) nova ciência.

A questão a ser levantada é qual destes três modelos mais se aplica ao atual estágio da Hidrogeomorfologia. $\mathrm{O}$ primeiro e o segundo modelo (Figura $2 \mathrm{a}$ e $2 \mathrm{~b}$ ) podem ser considerados os mais praticados na atualidade, incorporando a água (processo hidrológico) como agente modelador da paisagem ou incorporando as formas da paisagem (geomorfologia) nos estudos dos processos hidrológicos. Um exemplo dessa intersecção/sobreposição das duas ciências pode ser observado de maneira sistemática na Figura 3. Ao estudar os processos hidrológicos de uma bacia, neste caso o pico de vazão, tem-se uma variação da intensidade deste pico condicionada à forma da bacia. Assim, a bacia adquiriu uma determinada forma, objeto de estudo da geomorfologia, que por sua vez pode explicar a variação temporal e espacial de um processo hidrológico. Outro exemplo do trabalho conjunto pode ser demonstrado no estudo de eventos hidrológicos pretéritos, cujas feições resultantes permitem reconstruir sua frequência e magnitude. Dessa maneira, pode-se compilar um banco de dados de eventos hidrológicos que vai além de séries históricas obtidas por meio de monitoramento. A medição do transporte de sedimentos feitos inicialmente por hidrólogos pode auxiliar 
no entendimento das taxas de denudação e evolução da paisagem.

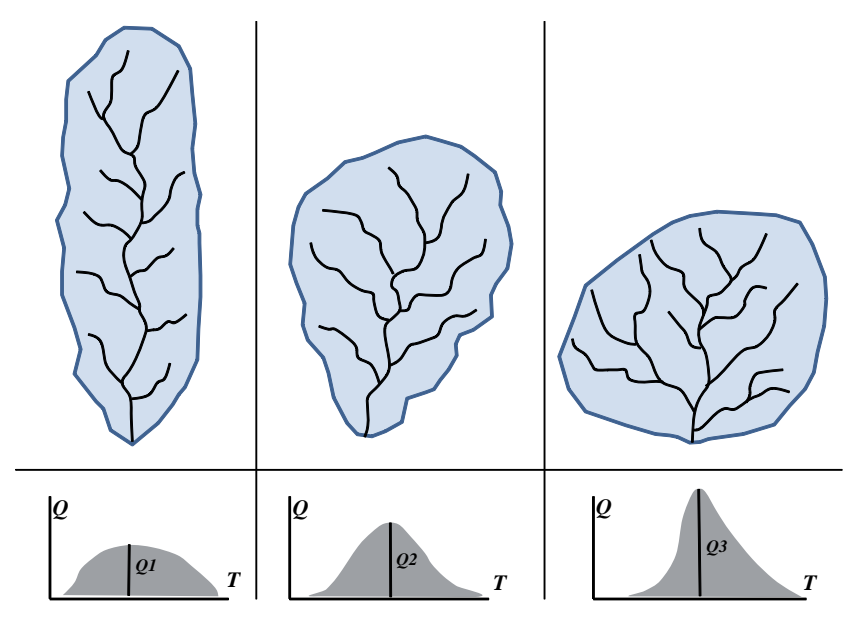

Figura 3 - Influência da forma da bacia nos processos hidrológicos. Fonte: Modificado de Patton (1988).

Dependendo do foco e escopo da pesquisa, ela será mais hidrológica ou mais geomorfológica, o que pode, contudo, incorporar as duas ciências. Neste sentido a pesquisa poderá ser ligada a Geomorfologia Hidrológica (Goudie, 2004; Pradhan et al., 2005; 2006) ou a Hidrologia Geomorfológica, sendo a primeira mais usual.

Um debate semelhante percorre a ecohidrologia e hidroecologia. Kundzewicz (2002) comenta que, seguindo as regras da língua inglesa, pode-se interpretar o prefixo "eco" na ecohidrologia como uma modificação da palavra hidrologia, ou seja, passa a noção que se trata mais de hidrologia do que ecologia. De maneira similar, "hidro" em hidroecologia modifica a palavra ecologia dando uma noção que trata mais de ecologia. Por outro lado, essa lógica não necessariamente se aplica as disciplinas científicas, pois existem termos como biofísica ou bioquímica, mas não fisicobiologia ou químicobiologia.

Esta consideração pode ser aplicada à Hidrogeomorfologia, em que o prefixo "hidro" estaria modificando geomorfologia, para a qual seria dada maior ênfase. Contudo, a palavra geomorfohidrologia ou geomorhidrologia soaria estranha. Assim, mesmo com o prefixo "hidro", a Hidrogeomorfologia dá ênfase nos processos hidrológicos que modificam e permitem a evolução da paisagem (geomorfologia) pela ação da água, não favorecendo esta ou aquela ciência.

O terceiro modelo (Figura 2c) é o mais complexo, pois envolve a criação de uma nova ciência ou campo do conhecimento, com paradigmas e um corpo teórico e metodológico próprio que também incorpora elementos da hidrologia e geomorfologia.
Como a Hidrogeomorfologia é ainda uma ciência emergente (Sidle e Onda, 2004), estas questões ainda não se apresentam de maneira clara nas pesquisas que vem sendo desenvolvidas com escopo hidrogeomorfológico. $\mathrm{Na}$ tentativa de contribuir com a elucidação do conceito de hidrogeomorfologia, o presente trabalho propõe a seguinte definição: a Hidrogeomorfologia é uma ciência que busca compreender como os processos hidrológicos contribuem para a formação e evolução da paisagem e ainda como as formas de relevo condicionam ou controlam os processos hidrológicos em diferentes escalas temporais e espaciais.

A Hidrogeomorfologia possui assim fundamentos da hidrologia e da geomorfologia, mas deve também possuir elementos próprios. Dessa maneira, um processo hidrológico propicia a modificação, evolução ou formação de uma feição que por sua vez condiciona a intensidade, magnitude, duração do processo hidrológico. Ou seja, o processo modifica a forma que por sua vez condiciona o processo. Neste contexto, Okunishi (1994) exemplifica que o fluxo de água sobre uma superfície móvel (encosta inclinada ou superfície de fundo de um canal) provoca a movimentação de sedimentos e consequentemente alterações topográficas, que por sua vez irão controlar as características do fluxo de água.

\section{Processos Hidrogeomorfológicos}

De acordo com Montgomery e Bolton (2003) as inundações e os deslizamentos podem ser considerados como processos hidrogeomorfológicos. Para Hungr et al. (2001), os processos hidrogeomorfológicos podem ser as inundações, fluxos hiperconcentrados e fluxos de detritos (debris flow). Wilford et al. (2004) argumentam que a diferenciação entre estes três tipos de processos pode ser feita pelo volume de sedimentos depositados relativos ao tamanho do canal e a orientação dos clastos. Para estes autores, as inundações possuem a concentração de sedimentos menor que $20 \%$ e a orientação do sedimento depositado é perpendicular ao fluxo. Os fluxos hiperconcentrados possuem concentração de $20 \%$ a $47 \%$ e imbricação pobre. Já os fluxos de detritos não possuem um único sentido de imbricação. Geralmente os blocos maiores são alinhados perpendicularmente ao fluxo e os seixos e blocos menores alinhados paralelamente. Wilford et al. (2005) propõem outros valores para a concentração de sedimentos. As inundações possuem concentração que varia de $1 \%$ e $40 \%$, os fluxos hiperconcentrados de $40 \%$ a $70 \%$ e os fluxos de detritos de $70 \%$ a $90 \%$. 
Além dos três processos acima citados, Sakals et al. (2006) incluem avalanches de neve e queda de blocos como processos hidrogeomorfológicos. Já Marchi et al. (2010) elencam apenas dois processos, os fluxos de detritos e os fluxos hiperconcentrados.

Com base nos trabalhos acima, nota-se que se podem classificar os processos hidrogeomorfológicos em três tipos principais: inundações, fluxos hiper-concentrados e fluxos de detritos. Estes três processos ainda carecem de entendimento do seu mecanismo e de seus impactos no sistema hidrológico e geomorfológico, podendo a Hidrogeomorfologia contribuir para elucidar estas lacunas teórico-metodológicas. Ressalta-se que qualquer processo hidrológico que modifica a paisagem e é simultaneamente condicionado por ela pode ser considerado hidrogeomorfológico. Por outro lado, os três processos acima citados se destacam por propiciarem maiores modificações na paisagem em curtos espaços de tempo. Além disso, são os que aparecem na literatura classificados explicitamente como hidrogeomorfológicos.

Por fim, para compreender estes processos, deve-se fazer uso de métodos e pressupostos teóricos da hidrologia bem como da geomorfologia, corroborando assim com a ideia da Hidrogeomorfologia como uma nova ciência (Figura 4). Por outro lado, os limites (L) de interação dentre as dimensões hidrológicas e geomorfológicas com a dimensão hidrogeomorfológica e até mesmo entre si ainda permanecem difusos.

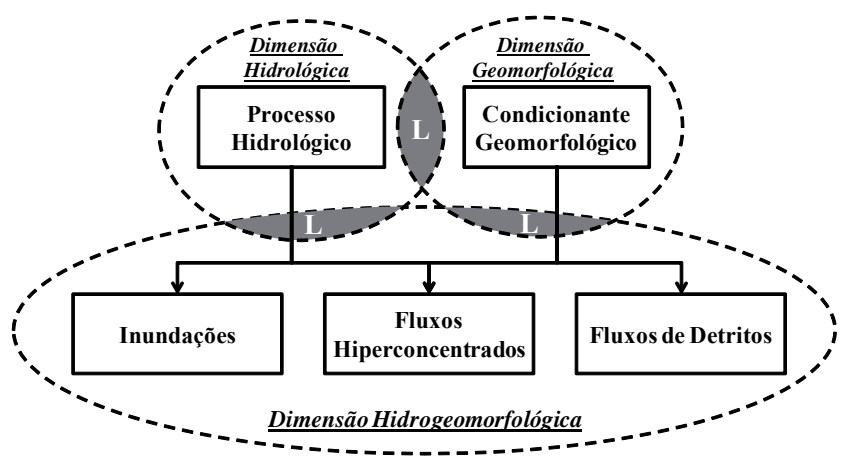

Figura 4 - Interação entre as dimensões hidrológicas, geomorfológica e hidrogeomorfológica.

Diante do exposto, pode-se dizer que a Hidrogeomorfologia é uma nova ciência, mas ainda carece de um amadurecimento teórico, especialmente no que tange a definir qual é o seu objeto, pois conforme Santos (1996) o corpus de uma disciplina deve estar subordinado ao objeto.

\section{A busca do objeto}

Scheidegger (1973) demonstrou a aplicação da Hidrogeomorfologia no contexto da geomorfologia de sua época (década de 60): erosão fluvial e superficial, efeito da tectônica no sistema fluvial (represamento, mudança do curso), infiltração e percolação de águas subterrâneas, estabilidade e formação de encosta e interação entre o sistema costeiro com o oceânico.

Silde e Onda (2004) enumeraram os seguintes temas chave desenvolvidos por pesquisas hidrogeomorfológicas: processos de escoamento superficial influenciados pela litologia e geomorfologia, processos erosivos superficiais ligados a canais; fatores de modelagem hidrológica que afetam a deflagração de deslizamentos e avaliação das propriedades hidrológicas dos solos associados a deslizamentos e a interação entre precipitação e ambiente terrestre. Ainda conforme Sidle e Onda (2004), os avanços atuais da Hidrogeomorfologia podem contribuir para estudos nas seguintes temáticas: desenvolvimento sustentável, desastres naturais e medidas mitigadoras, efeitos da mudança climática e planejamento territorial. Possivelmente as contribuições mais importantes da Hidrogeomorfologia sejam os estudos conjunto dos processos hidrológicos e geomorfológicos em nível de bacia, pois a avaliação destes processos em escalas temporais e espaciais correlatas permite levantar questões relevantes para a sua explicação e contribuir para a gestão da bacia.

Brinson (1993) e Shafer e Yozzo (1998) desenvolveram o "Guia de Avaliação Hidrogeomorfológica (HGM) para Ambientes Estuarinos com influência de Maré”. Segundo estes autores, a avaliação hidrogeomorfológica é um grupo de conceitos e métodos utilizados no desenvolvimento de índices que permitem a avaliação da funcionalidade destes ambientes por intermédio de três focos principais: hidrodinâmica, geomorfológica e fonte de água. $\mathrm{O}$ foco hidrodinâmico refere-se à energia e a dinâmica do fluxo da água dentro do ambiente; o foco geomorfológico trata da paisagem e evolução geológica da mesma e a fonte de água trata da fonte primária de água (precipitação, águas superficiais ou águas subterrâneas). Shafer e Yozzo (1998) ainda destacam oito funções principais para estes ambientes, agrupadas em dois grupos: funções hidrogeomorfológicas e funções de habitat. As funções hidrogeomorfológicas são a atenuação dos efeitos da amplitude de maré, ofertas de nutriente e troca de carbono e sedimentação. NRCS (2008) comentou que este sistema de classificação Hidrogeomorfológica dá ênfase em atributos hidrológicos e geomorfológicos, ao invés de apenas limitar-se a atributos bióticos dos ambientes estuarinos.

Ojeda et al.(2007) propuseram um Índice Hidrogeomorfológico para a avaliação do estado ecológico do sistema fluvial. Este índice baseia-se em três parâmetros: qualidade funcional do sistema fluvial, qualidade do canal e qualidade da zona ripária. Para cada um desses parâmetros são atribuídos valores que determinam este índice hidrogeomorfológico, que permitem avaliar a "vitalidade" dos sistemas fluviais e os impactos antrópicos sobre os mesmos. 
Marini e Piccolo (2005) e Marini et al. (2009) elaboraram cartas hidrogeomorfológicas de diferentes bacias hidrográficas argentinas. Segundo estes autores, as cartas hidrogeomorfológicas permitem determinar condições de escoamento em uma bacia, resultantes da combinação de diferentes processos que definem um comportamento hidrológico. Para isto estas cartas devem contemplar informações sobre as características hidrológicas do terreno, a circulação superficial da água, os tipos e formas de escoamento, características fisiográficas das encostas da bacia hidrográfica, tipo de vegetação, entre outros. Por fim, a carta hidrogeomorfológica deve contemplar os fenômenos geomorfológicos que afetam os cursos d'água.

Investigando a bacia do rio Quequen Salado (Argentina) Marini e Piccolo (2005) contemplaram em sua carta hidrogeomorfológica: 1) Características hidrológicas do terreno (área de infiltração média, baixa ou muito baixa); 2) Morfologia Fluvial, que se divide em: 2a) tipo de escoamento (perenes ou intermitentes), 2b) características dos canais (fundo arenoso, abandonado ou $\mathrm{com} / \mathrm{sem}$ margens), 2c) natureza do fundo (fundo plano ou com vegetação), 2d) Corpos d'água (lagos permanentes ou não) 2e) dinâmica das vertentes (deslizamentos estabilizados); 3) Cobertura vegetal (entre $40-50 \%$ ou entre $90-100 \%$; 4) Elementos estruturais (anticlinal ou sinclinal); 5) Topografia (áreas urbanizadas, limite da bacia, direção da vertente). A partir destes elementos, foi inferido sobre a dinâmica hidrogeomorfológica da bacia, sugerindo medidas corretivas como revitalização de rios, áreas que necessitam retificação, aumento da mata ciliar, reflorestamento de determinadas áreas da bacia, entre outras medidas. Marini et al. (2009) fizeram um estudo semelhante, mas enfatizando o controle geológico e características litológicas nos processos hidrológicos, especialmente o controle geológico na direção dos rios.

Nota-se que este tipo de mapeamento mantém o foco no momento do estudo, possuindo uma limitação temporal e espacial, não apresentando a ideia de processo ou evolução. Dessa maneira, os processos não são estudados continuamente, mas sim inferidos e espacializados. Assim, este método hidrogeomorfológico e o índice hidrogeomorfológicos diferem conceitualmente e metodologicamente das abordagens sugeridas por Scheidegger (1973), Sidle e Onda (2004) e o presente trabalho.

Os trabalhos supracitados são os que demonstraram ou criaram um método hidrogeomorfológico próprio como o Índice Hidrogeomorfológico ou o Método Hidrogeomorfológico (HGM). Além dessas abordagens, pesquisas relacionadas à interação de ajuste de canais a diferentes padrões de vegetação e disponibilidade de sedimentos (Hupp e Osrterkamp, 1996, Morais et al.,
2008, Kupfer et al.,2010) têm se caracterizado dentro de um escopo dito hidrogeomorfológico.

No Brasil, pesquisas desenvolvidas por Suertegaray et al. (1996), Thomaz e Ross (2006) e Briguenti et al. (2007), apresentaram estudos intitulados de hidrogeomorfológicos, sem, no entanto, apresentá-las ou interligá-las ao conceito de Hidrogeomorfologia.

\section{O objeto da Hidrogeomorfologia}

Conforme demonstrado acima, diversos estudos têm aplicado métodos hidrogeomorfológicos ou intitulado o trabalho como hidrogeomorfológico, sem o devido cuidado com o objeto da Hidrogeomorfologia. De fato, por se tratar de uma nova ciência, seu objeto ainda não foi claramente definido. Por outro lado, para a Hidrogeomorfologia ser considerada uma ciência, ela deve possuir um objeto. Com base nos estudos e bibliografias aqui apresentadas, o presente trabalho propõe que o objeto de estudo da Hidrogeomorfologia são os processos hidrogeomorfológicos. Definindo assim o objeto, os estudos de escopo hidrogeomorfológico passam a ser analisados de outra forma. O que se observa não é mais se podem ou não serem enquadrados dentro da definição clássica de Hidrogeomorfologia, mas se abordam ou não o objeto, independendo do método.

Ressalta-se que estes processos não são apenas os apresentados no item 4 (inundações, os fluxos hiperconcentrados e os fluxos de detritos), apesar de serem os que mais aparecem em estudos como processos hidrogeomorfológicos. De uma forma abrangente, os processos hidrogeomorfológicos devem ser aqueles que exercem controle tanto sobre a evolução e formação da paisagem como sobre os processos hidrológicos (Figura 5). Justamente por isso os mesmos não se encaixam apenas nos três tipos acima elencados.

Segundo Silde e Onda (2004), questões relacionadas à Hidrogeomorfologia carecem de estudos aprofundados e precisam ser mais bem respondidas, como estudos associados a fluxo preferencial e transporte de materiais em diferentes escalas temporais e espaciais; interação entre encosta, canal e zona ripária; alterações no fluxo superficial e erosão associados a diferentes uso do solo; processos erosivos; avaliação dos efeitos das mudanças climáticas nos processos costeiros; entre outros. Neste contexto, cita-se o trabalho de Santos (2009) que, por meio do monitoramento e modelagem dos processos hidrogeomorfológicos, determinou os mecanismos de geração de escoamento e a conectividade hidrológica em uma pequena bacia, destacando-se como um dos trabalhos pioneiros na Hidrogeomorfologia brasileira, principalmente por abordar a gênese e dinâmica dos processos, ou seja, tratando os processos como objeto. 


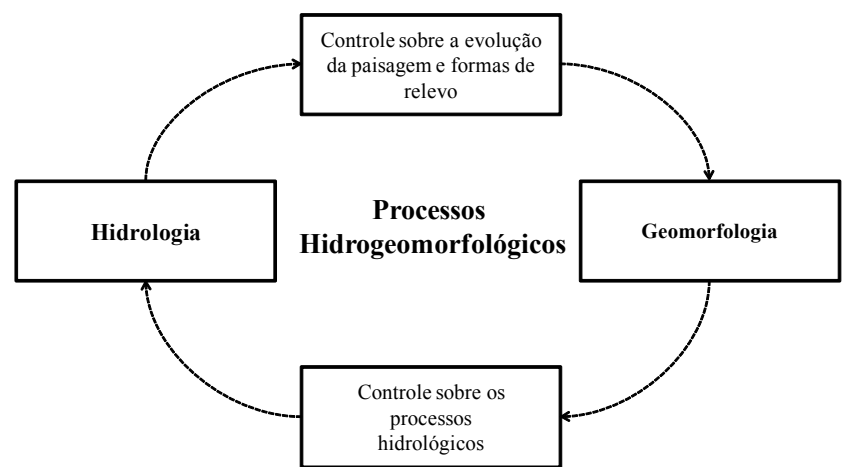

Figura 5 - Diagrama do conceito de Hidrogeomorfologia e do objeto proposto no presente trabalho

Sidle (2004) argumenta que devido às particularidades da Hidrogeomorfologia, não se deve perder de vista o foco na compreensão dos processos, apesar da crescente popularidade dos mega-modelos ou da fascinação pelas novas técnicas. Dessa maneira, apesar dos constantes avanços na técnica, que contribuem para a busca de novos métodos, não se deve perder o foco do objeto, para que não se tenha tantas Hidrogeomorfologias quanto hidrogeomorfólogos.

\section{Conclusões}

O presente trabalho apresentou, em primeiro lugar, uma revisão bibliográfica sobre o termo Hidrogeomorfologia. Este termo foi proposto/utilizado pela primeira vez por Scheidegger (1973) e, especialmente nos últimos anos, é utilizado com maior frequência. Observa-se na revisão bibliográfica que os periódicos relacionados à hidrologia atêm-se com maior recorrência a essa temática, fato também observado em um eixo temático sobre Hidrogeomorfologia ocorrido em um simpósio internacional de geomorfologia, que teve seus principais artigos publicados em um periódico de hidrologia.

Esta nova ciência ou ramo do conhecimento trata da interação entre os processos hidrológicos e os geomorfológicos, contudo, como esta interação ocorre ainda não está claro.

Assim, foram apresentados diversos estudos de caso de pesquisas que envolvem a Hidrogeomorfologia como temática principal. Ficou demonstrado que a grande parte destes estudos não trata de processos hidrológicos, nem como os mesmos modificam ou são condicionados pela (geo) morfologia da paisagem. Dessa maneira, não deveriam ser considerados, a priori, como estudos hidrogeomorfológicos. Por outro lado, a análise crítica dos estudos aqui apresentados careceu de fundamentação, pois o objeto da Hidrogeomorfologia ainda não esta claro. Contribuindo nesta direção, o presente trabalho, definiu-o como sendo os processos hidrogeomorfológicos. Dessa maneira, a análise dos trabalhos não fica condicionada ao método, que por sua vez está limitado espacial e temporalmente, mas fica embasada no objeto, que por sua vez acompanha toda a existência dessa nova ciência.

Pesquisas relacionadas à Hidrogeomorfologia ainda são recentes no Brasil e as que abordam esta temática não tem enfocado os processos hidrológicos e suas implicações na transformação/evolução da paisagem. Neste sentido, o presente trabalho buscou, por último, salientar a importância dessa nova forma de conhecimento e a necessidade de se consolidar um corpo teórico metodológico próprio da Hidrogeomorfologia.

\section{Agradecimentos}

Os autores agradecem aos membros do Laboratório de Hidrogeomorfologia da Universidade Federal do Paraná e do Laboratório de Hidrologia da Universidade Federal de Santa Catarina pelas discussões, comentários e críticas ao presente trabalho. O primeiro autor agradece ao Programa REUNI/ UFPR pela concessão da bolsa de pesquisa.

\section{Referências bibliográficas}

BABAR, M. Hydrogeomorphology: Fundamentals Applications and Techniques. Nova Delhi: NIPA, 2005, $274 \mathrm{p}$.

BRIGUENTI, E. C.; CARPI JR., S.; DAGNINO, R. S. Identificação de riscos hidrogeomorfológicos em unidades geossistêmicas da bacia do ribeirão das Anhumas, Campinas/ SP. In: Anais do XII Simpósio Brasileiro de Geografia Física Aplicada: Natal, p. 1629-1648, 2007

BRINSON, M. M. A Hydrogeomorphic Classification for Wetlands. Wetlands Research Program Technical Report WRP-DE-4, U.S. Army Corps of Engineers, 1993, 101p.

DEBARRY, P. A. Watershed: processes, assessment and management. John Wiley \& Sons: New Jersey, 2004. 700p.

GOUDIE, A. Encyclopedia of Geomorphology. Routledge: London, 2004, 1200 p.

GREGORY, K. J. Fluvial geomorphology. Progress in Physical Geography. v. 3, p. 274-282, 1979 b.

GREGORY, K. J. Hydrogeomorphology: how applied should we become? Progress in Physical Geography, v.3, p. 84-101, 1979a.

HUGGET, R. J. Fundamentals of Geomorphology. Routledge: London, 2005, 386p.

HUNGR, O.; EVANS, S. G.; BOVIS, M. J.; HUTCHINSON, J.N. A review of the classification of landslides of the flow type. Environmental and Engineering Geoscience, v. 7, n. 3, p. 221-238, 2001.

HUPP, C. R.; OSRTERKAMP, W. R. Riparian vegetation and fluvial geomorphic processes. Geomorphology, n. 14, p. 277295, 1996. 
KUNDZEWICZ, Z. W. Ecohydrology - seeking consensus on interpretation of the notion. Hydrological Sciences, v. 47, n. 5, p. 799-804, 2002.

KUPFER, J. A.; MEITZEN, K. M.; PIPKIN, A. R. Hydrogeomorphic controls of early post-logging successional pathways in a southern floodplain forest. Forest Ecology and Management, n. 259, p. 1880-1889, 2010.

MARCHI, L.; CAVALLIM.; D'AGOSTINO, V.Hydrogeomorphic processes and torrent control works on a large alluvial fan in the eastern Italian Alps. Natural Hazards and Earth System Sciences, n. 10, p. 547-558, 2010.

MARINI, F, M.; PICCOLO, M. C. Hidrogeomorfología de la cuenca del río Quequén Salado, Argentina. Investigaciones Geográficas, n. 37, p. 59-71, 2005.

MARINI, F, M.; SCHILliZI, R.; PICCOLO, M. C. Carta hidrogeomorfológica de la cuenca superior de los arroyos Pillahuincó Grande y Pillahuincó Chico, Buenos Aires, Argentina. Revista de Geografía Norte Grande, n. 42, p. 71-80, 2009.

MONTGOMERY, D. R.; BOLTON, S. M. Hydrogeomorphic Variability and River Restoration. In: WISSMAR, R. C. e BISSON, P. A. (ed.) Strategies for Restoring River Ecosystems: Sources of Variability and Uncertainty in Natural and Managed Systems. American Fisheries Society Publication: Maryland, p. 39-80, 2003.

MORAIS, R. P. AQUINO, S. LATRUBESSE, E. M. Controles hidrogeomorfológicos nas unidades vegetacionais da planície aluvial do rio Araguaia, Brasil. Acta Scientiarum, Biological Sciences. v. 30, n. 4, p. 411-421, 2008.

NRCS - Natural Resources Conservation Sciences. Hydrogeomorphic Wetland Classification System: An Overview and Modification to Better Meet the Needs of the Natural Resources Conservation Service. Technical Note No. 190-8-76. 2008. 10p.

OJEDA, A. O.; FERRER, D. B.; BEA, E. D.; MUR, D. M.; FABRE, M. S.; NAVERAC, V. A.; ARNEDO, M. T. E.; GARCÍA, D. G.; MATAUCO, A. I. G.; GIL, L. S.; GIL, N. S. Un Índice Hidrogeomorfológico (IHG) para la evaluación del estado ecológico de sistemas fluviales. Geographicalia, n. 52, p. 113-141, 2007.

OKUNISHI, K. Conceptand methodology of hydrogeomorphology. Transactions, Japanese Geomorphological Union, 15A, p. 5-18, 1994.

OKUNISHI, K. Hydrogeomorphological interactions: a review of approach and strategy. Transactions, Japanese Geomorphological Union, 12, p. 99-116, 1991.

PANIZZA, M. Environmental Geo-morphology. In: Developments in Earth Surface Processes 4, Elsevier: Amsterdan. 1996, 285p.

PATTON, P.C. Drainage basin mor-phometry and floods. In: BAKER, V.R.; KOCHEL, R.C.; PATTON, P.C. (ed.) Flood Geomorphology. New York: John Wiley \& Sons, Cap. 3, p. 51-64. 1988.
PRADHAN, N.R,; TACHIKAWA, Y.; TAKARA, K.Adownscaling method of topographic index distribution for matching the scales of model application and parameter identification. Hydrological Processes. n. 20, p. 1385-1405. 2006b.

PRADHAN, N. R,; TACHIKAWA, Y.; TAKARA, K. Downscaling methods of flow variables for scale invariant routing model. Annual Journal of Hydraulic Engineering, v.50, p. 109-114, 2006a.

RICHARDS, K. Fluvial Geomorphology. Progress in Physical Geography, v. 12, p. 435-456, 1988.

SAKALS, M. E.; INNES, J. L.; WILFORD, D. J.; SIDLE, R. C.; GRANT, G. E. The role of forests in reducing hydrogeomorphic hazards. Forest Snow Landscape Research, v. 80 n. 1, p. 1122, 2006.

SANTOS, I. Monitoramento e modelagem de processos hidrogeomorfológicos: Mecanismos de geração de escoamento e conectividade hidrológica. Florianópolis: UFSC/ CFH/GCN, 2009. 167f. Tese (Doutorado em Geografia) - Programa de Pós-Graduação em Geografia, Universidade Federal de Santa Catarina.

SANTOS, M. A natureza do espaço: técnica e tempo, razão e emoção. $2^{a}$ ed. São Paulo: HUCITEC, 1997

SCHEIDEGGER, A. E. Hydrogeomor-phology. Journal of Hydrology, n. 20, p. 193-215, 1973

SHAFER, D. J.; YOZZO, D. J. National Guidebook for Application of Hydrogeomorphic Assessment to Tidal Fringe Wetlands. Wetlands Research Program, Technical Report WRP-DE-16, 1998, 80p.

SIDLE, R. C. New Concepts in Hydrogeomorphic Processes Across Various Scales of Space and Time. Transactions, Japanese Geo-morphological Union, v. 25, n. 4. p. 331-340, 2004.

SIDLE, R. C.; ONDA, Y. Hydrogeomorphology: overview of an emerging science. Hydrological Processes, n. 18, p. 597-602, 2004.

SUERTEGARAY, D. M. A.; VERDUM, R.; MEDEIROS, R. M.; GUASSELLI, L.; FRANK, M. W. Caracterização hidrogeomorfológica e uso do solo em áreas de ocorrência de areais: São Francisco de Assis/Manuel Viana. In: Anais do VIII Simpósio Brasileiro de Sensoriamento Remoto, Salvador: INPE, p. 663-669, 1996.

THOMAZ, E. L.; ROSS, J, L. S. Processos hidrogeomorfológicos em vertente com solos argilosos rasos em Guarapuava-PR, Brasil. Revista Brasileira de Geomorfologia - Ano 7, n. 2, p. 23-38, 2006.

WILFORD, D. J; SAKALS M. E.; INNES, J. L.; SIDLE, R.C.; BERGERUD, W. A. Recognition of debris flow, debris flood and flood hazard through watershed morphometrics. Landslides, n. 1, p. 61-66, 2004.

WILFORD, D. J.; SAKALS, M. E.; INNES, J. L. Forest management on fans: hydrogeomorphic hazards and general prescriptions. B. C. Min. For., Res. Br., Victoria, B. C. Land Management Handbook. n. 57, 2005, 42p. (http://www.for.gov. bc.ca/hfd/pubs/Docs/Lmh/Lmh57.htm) 